\title{
PEMETAAN DIGITAL LOKASI SENTRA PERTANIAN DAN PERIKANAN UNTUK MENARIK MINAT INVESTOR PADA KABUPATEN DEMAK KOTA DENGAN PLATFORM ANDROID
}

\author{
M. August Rohman \\ Sekolah Tinggi Elektronika dan Komputer \\ Febryantanahuji \\ Sekolah Tinggi Elektronika dan Komputer \\ febryan@stekom.ac.id \\ Zaenal Mustofa \\ Sekolah Tinggi Elektronika dan Komputer
}

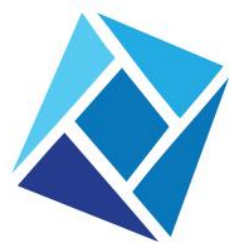

\section{Jurnal Nusantara Aplikasi Manajemen Bisnis}

http://ojs.unpkediri.ac.id/index.php/ manajemen/index

E-ISSN : 2528-0929

P-ISSN : 2549 - 5291

Diterima: 31 Maret 2018

Revisi : 16 April 2018

Disetujui: 18 April 2018

https:doi.org10.29407nusamba.v3i1. 12028

\section{Abstract}

Demak regency is one of goverment institute which act to make and accompany all section of agriculture and fishery in Demak and arround. Now, facilities and infrastructures in delivery information of agriculture and fishery's product which available are still simple and konventional. The aim of this research is to give solution which be related to information system and promotion, among others yields information, location of agriculture and fishery centers which can be delivered to investor who want to join investment even purchases agricultural and fishery products with maximum and fast. This research method using model approach Research and Development $(R \& D)$ in 6 stages, that are research and information collecting, planning, develop premilinary form of product, preliminary field testing, main product revision, and main field testing. The result of this study show that the using of android based mapping information systems has met the needs of farmers and investors in conveying information. Among others informations of investment even for purchasing agricultural and fishery products easily by smartphone based android in order to information can be delivered to potential buyers / investors.

\section{Abstrak}

Kabupaten Demak merupakan salah satu instansi pemerintahan yang bekerja untuk menciptakan dan mendampingi semua kalangan pertanian dan perikanan yang ada di daerah Demak dan sekitarnya. Untuk saat ini fasilitas dan prasarana dalam penyampaiaan informasi hasil pertanian dan perikanan yang tersediakan saat ini masih sederhana dan konvensional, Tujuan penelitian ini adalah untuk memberikan solusi masalah yang berkaitan dengan sistem informasi dan promosi diantaranya informasi hasil panen, lokasi sentra pertanian dan perikanan yang bisa tersampaikan kepada investor yang ingin ikut andil dalam penanaman modal bahkan untuk pembelian hasil pertanian dan perikanan yang ada dengan maksimal dan cepat. Metode penelitian ini menggunakan pendekatan model Research and Development $(R \& D)$ dengan 6 tahapan yaitu research and information collecting, planning, develop premilinary form of product, preliminary field testing, main product revision, main field testing. Hasil penelitian ini menunjukan bahwa penggunaan Sistem informasi pemetaan berbasis android telah memenuhi kebutuhan para petani dan investor dalam menyampaikan informasi diantaranya informasi dalam penanaman modal bahkan untuk pembelian hasil pertanian dan perikanan dengan mudah yang dapat diakses melalui smartphone berbasis android agar informasi dapat tersampaikan kepada calon pembeli / investor.

Keywords: Manajemen Informatika, Aplikasi Manajemen, Android, Sistem Informasi. 


\section{PENDAHULUAN}

Saat ini media berbasis elektronik sangat berperan dalam menentukan produktifitas sebuah instansi dalam segala jenis bidang. Selain untuk meningkatkan profit juga dapat membantu sebuah instansi dalam melakukan promosi. Sistem Infomasi online dapat mempromosikan sebuah instansi tanpa terbatas ruang dan waktu, dengan lebih cepat dan mudah. (Febryantahanuji, 2017). Selain website terdapat pula sistem informasi yang dapat membantu dalam meningkatkan produktivitas sebuah instansi atau perusahaan, yaitu GIS. GIS (Geographic Information System) menjadi salah satu perangkat lunak yang digunakan untuk melakukan pemetaan secara real time dan dapat diterapkan pada sebuah aplikasi mobile ber-platform android. Teknologi memegang peran penting di era modernisasi seperti pada saat ini, dimana teknologi telah menjadi bagian yang tidak dapat dipisahkan dalam kehidupan sehari-hari. Salah satunya adalah handphone, yang ditandai lahirnya teknologi smartphone. Kelebihan perangkat smartphone adalah adanya teknologi GPS (Global Positioning System) yang telah terintegrasi. Hal ini memudahkan pengembang memanfaatkan nilainilai geografis dari teknologi GPS dapat memberikan informasi posisi pengguna, apa saja yang dekat dengan pengguna, arah rute menuju suatu lokasi, dan lain-lain. Android merupakan salah satu platform dari perangkat smartphone. Salah satu keutamaan dari Android yaitu lisensinya yang bersifat terbuka (open source) dan gratis (free) sehingga bebas untuk dikembangkan karena tidak ada biaya royalti maupun didistribusikan dalam bentuk apapun. Selain itu Android juga media yang dapat mengeksplore kemampuan GIS lewat Google Map.

Kabupaten Demak adalah salah satu daerah di Jawa Tengah yang mempunyai keindahan alam yang sangat beragam, yaitu terdapat sumber daya alam yang memadai, dimana struktur tanah yang cocok untuk ditanami berbagai macam jenis tanaman serta sarana pengairan yang mendukung, dan terdapat juga potensi lahan yang cocok untuk dijadikan tempat budidaya ikan kolam maupun ikan tambak, serta jenis air yang mendukungnya.

Dari potensi tersebut, terdapat berbagai macam hasil pertanian dan perikanan yang cukup bagus. Di Kabupaten Demak sendiri terkenal dengan lumbung padinya sehingga Demak merupakan salah satu penghasil dan pemasok bahan pangan terbesar ke-3 di Jawa Tengah, selain itu Demak mempunyai ciri khas tersendiri yaitu dengan pusat budidaya Jambu Delima dan Belimbing, yang tersebar di beberapa Kecamatan yang ada di Kabupaten Demak.

Adanya pertanian dan perikanan yang ada diharapkan dapat menaikkan nilai tambah tersendiri bagi Kabupaten Demak. Hanya saja kurangnya informasi tentang lokasi sentra pertanian dan perikanan disetiap sentra-sentra yang tersebar di Kabupaten Demak membuat masyarakat luas belum begitu mengenalinya. Dibandingkan dengan sentra pertanian dan perikanan yang ada diluar Kabupaten Demak, sentra yang ada masih kesulitan dalam mendapatkan konsumen tetap, padahal hasil panen petani bagus dan berkualitas. Karena masih menggunakan metode promosi yang konvensional, yaitu dengan informasi dari mulut ke mulut, dan informasi tersebut hanya di tempelkan di kantor kecamatan dan kantor kelurahan, jadi jangkauan pemasarannya hanya di daerah lokal saja, Sehingga investor dan konsumen yang ingin membeli hasil panen kesulitan mendapatkan informasi potensi yang ada, karena harus mendatangi setiap kantor Kecamatan dan kantor kelurahan setempat, sehingga hanya tengkulak lokal saja yang mengetahui potensi tersebut dan mendominasi penjualan hasil panen petani yang dirasa sangat merugikan bagi petani, karena tingkat harga jual hasil panen ditentukan oleh kelompok tengkulak tersebut, dan tidak ada persaingan harga yang bagus dan sehat, bahkan harga yang ditawarkan sangat rendah dan tentunya petani sangat merugi.

Hal yang harus dilakukan untuk mengembangkan sektor pertanian dan perikanan menjadi lebih maju dan menghindari perkembangan tengkulak lokal yang semakin mendominasi pemasaran hasil panen adalah dengan membuat sebuah media yang murah dan efektif, sehingga petani dan Dinas terkait dapat aktif berpartisipasi didalam rancangan program pengembangan ini. Dari masalah tersebut, penulis berinisiatif untuk memberikan solusi agar didapat subuah informasi yang interaktif dan real time dengan kemajuan teknologi yang ada,. Yang bertujuan agar informasi dapat tersebar luas sehingga 
1. Banyak tengkulak dari luar daerah akan ikut bersaing dengan tengkulak lokal, sehingga hasil panen di tingkat petani bisa lebih tinggi.

2. Investor bisa mengetahiu potensi lahan di Kabupaten Demak, sehingga membuka peluang bagi investor untuk melakukan investasi di Kabupaten Demak.

Untuk mewujudkan tujuan diatas maka dibuatnya aplikasi peta digital untuk pemetaan sentra Pertanian dan Perikanan di Kabupaten Demak pada platform Android.

\section{KAJIAN PUSTAKA}

\section{A. Kajian Penelitian}

1. Jurnal Nasional menurut Febryantahanuji (2017) judul penelitian Kesesuaian Jenis Tanah Terhadap Tanaman Untuk Meningkatkan Produktivitas Bisnis Hasil Perkebunan Dengan Geoprocessing menyatakan bahwa dengan menggunakan Sistem Informasi Geografis (GIS) dapat dilakukannya klasifikasi kesesuaian tanah pada Kabupaten Boyolali sehingga dapat mengoptimalkan hasil produksi perkebunan yang ada di daerah tersebut.

2. Jurnal Internasional menurut Beate Stollberg dan Alexander Zipf (2008) judul penelitian Geoprocessing Services for Spatial Decision Support in the Domain of Housing Market Analyses menyatakan bahwa dengan menggunakan Sistem Informasi Geografis (GIS) dapat membantu menentukan sebuah keputusan untuk menganalisis perumahan dan pasar real estat.

3. Jurnal Nasional menurut Dimas Randi A.F. (2013). Dalam penelitian skripsinya menjelaskan bahwa tujuan penulis adalah Pemetaan Digital Lokasi Sentra Industri, dikarenakan sebelum penulis membuat aplikasi ini lokasi sentra indutri yang ada di Kabupaten Jepara belum begitu dikenal masyarakat luas, maka setelah dibuatnya aplikasi ini diharapkan:

a. Membantu user mengetahui berbagai jenis industri dan kerajinan di Kabupaten Jepara secara Real Time. Jadi saat user berada di Kabupaten Jepara, user dapat mencari lokasi sentra industri dan juga dapat mengetahui lokasi dimana user berada.

b. Dalam aplikasi yang dibangun belum terintegrasi dengan server, sehinga user masih direpotkan dalam mendpatkan data informasi yang terbaru.

4. Jurnal Nasional menurut Yaulie Riendengan. (2013). Dalam penelitiannya disebutkan sebelum adanya aplikasi ini masyarakat belum mengetahui informasi daerah rawan bencana secara lengkap, terperinci dan up to date, maka dengan dibuatnya aplikasi ini tujuan penelitian penulis adalah :

a. Aplikasi mobile android yang dapat memberikan informasi spasial wilayah rawan bencana banjir dan tanah longsor di Kota Manado.

b. Aplikasi ini dapat menampilkan informasi wilayah rawan bencana banjir dan tanah longsor pada peta Kota Manado.

c. Aplikasi ini dapat memberikan informasi perkiraan cuaca Sulawesi Utara.

Berdasarkan beberapa penelitian yang sudah dilakukan di atas dapat disimpulkan bahwa dengan penggunaan Sistem Informasi Geografis sangat membantu dalam penyampaian informasi terhadap publik, oleh karena itu penulis menggunakan GIS untuk membuat Pemetaan Digital Lokasi Sentra Pertanian Dan Perikanan Untuk Menarik Minat Investor.

\section{B. Landasan Teori}

Sistem Informasi Geografis

Sistem Informasi Geografis (bahasa Inggris: Geographic Information System (GIS) adalah sistem informasi khusus yang mengelola data yang memiliki informasi spasial (bereferensi keruangan). Para praktisi juga memasukkan orang yang membangun dan mengoperasikannya dan data sebagai bagian dari sistem ini. (Riyanto, 2010).

\section{METODE PENELITIAN}

Model pengembangan penelitian yang penulis lakukan yaitu dengan pendekatan model R\&D (research and development) dari Borg \& Gall (1983). Metode pengembangan sistem yang digunakan adalah Prototyping dan menghasilkan sebuah produk dalam bentuk Prototype. Sebuah Prototype akan memberikan gambaran tentang cara sistem yang akan berfungsi dalam bentuk lengkapnya. 


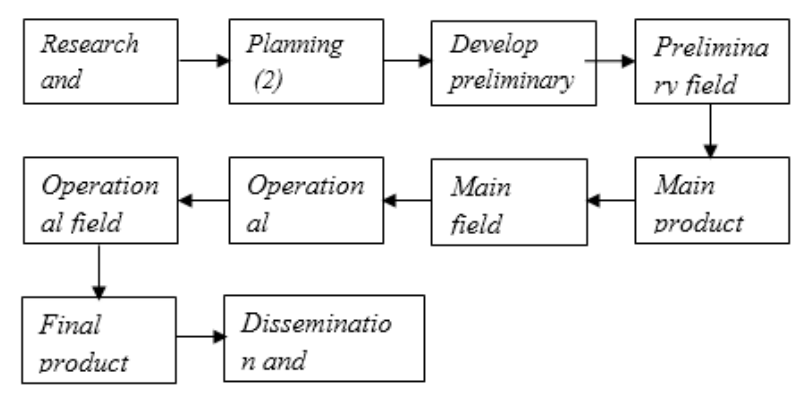

Gambar 1 Alur model R\&D Borg \& Gall 1983

Dari 10 tahapan yang dikemukakan oleh Borg \& Gall, penulis hanya menggunakan 6 tahapan saja untuk diterapkan dalam penelitian ini.

1. Penelitian dan pengumpulan data

a.

Melakukan wawancara dengan Petani, dinas pertanian dan perikanan di Kabupaten Demak guna memperoleh informasi - informasi yang dibutuhkan untuk gambaran spesifikasi produk yang diharapkan.

b. Melakukan observasi lapangan untuk mengetahui permasalahan yang ada.

c. Melakukan studi literatur guna mendapatkan teori - teori utama yang menunjang dalam rancangan bangun sistem.

d. Memilih metode penyelesaian yang tepat berdasarkan pengamatan dan keinginan calon pemakai dengan mempertimbangkan teknologi yang sesuai untuk diterapkan.

2. Planning (Perencanaan)

Menyusun rencana penelitian, meliputi kemampuan-kemampuan yang diperlukan dalam pelaksanaan penelitian, rumusan tujuan yang hendak dicapai dengan penelitian tersebut, desain langkah-langkah dari masalah penelitian, menerangkan beberapa spesifikasi didalam produk yang akan dibuat, serta menyusun langkah proses pembuatan mulai dari desain sampai menjadi produk, yang dituangkan didalam bentuk jadwal perencanaan yang terstruktur dan terorganisir.

3. Develop prelminary form of product (Pengembangan)

Untuk menghasilkan sistem kerja baru maka penulis membuat rancangan kerja baru yang dibuat badasarkan penilaian terhadap sistem kerja lama, sehingga dapat ditemukan kelemahankelemahan terhadap sistem lama tersebut dan kemudian dikembangkan menjadi sistem yang baru. Dalam pengembangan sistem dilakukan desain sistem melalui pembuatan Flow Chart Diagram, database yang digunakan, Use Case diagram, Activity Diagram, Sequence Diagram dan Desain Interface serta menyiapkan pedoman dan buku petunjuk, dan melakukan evaluasi terhadap kelayakan alat-alat pendukung.

4. Preliminary field testing.

Tahapan ini melakukan ujicoba lapangan awal dalam skala terbatas, dengan melibatkan subjek secukupnya hal ini pakar yang diwakili dosen yang berkompeten dibidangnya. Pada langkah ini dilakukan uji validasi desain. Apabila masih terdapat kekurangan akan dilakukan perbaikan sesuai masukan dari pakar.

5. Main product revision.

Melakukan perbaikan terhadap produk awal yang berupa desain sistem informasi yang dihasilkan hasil uji coba awal. Perbaikan ini sangat mungkin dilakukan lebih dari satu kali, sesuai dengan hasil yang ditunjukkan dalam ujicoba terbatas, sehingga desain sistem dinyatakan valid oleh pakar.

6. Main field testing.

Setelah lulus uji validasi oleh pakar dilakukan dengan pembuatan source code menjadi protoptype produk berupa software pemetaan digital lokasi sentra pertanian dan perikanan menggunakan teknologi platform android, yang selanjutnya akan dilakukan uji lapangan oleh stakholder yaitu calon user sampai mendapat rekomendasi baik dan efektif untuk digunakan. 


\section{JURNAL NUSAMBA VOL.3 NO.1 APRIL $\mid 2018$}

\section{HASIL DAN PEMBAHASAN}

Setelah dilakukan uji coba produk oleh validator, yang di wakili oleh pengguna dan melibatkan pakar yang berkompetensi di bidangnya. Berikut hasil produk yang dihasilkan:

1. Tampilan Icon Aplikasi

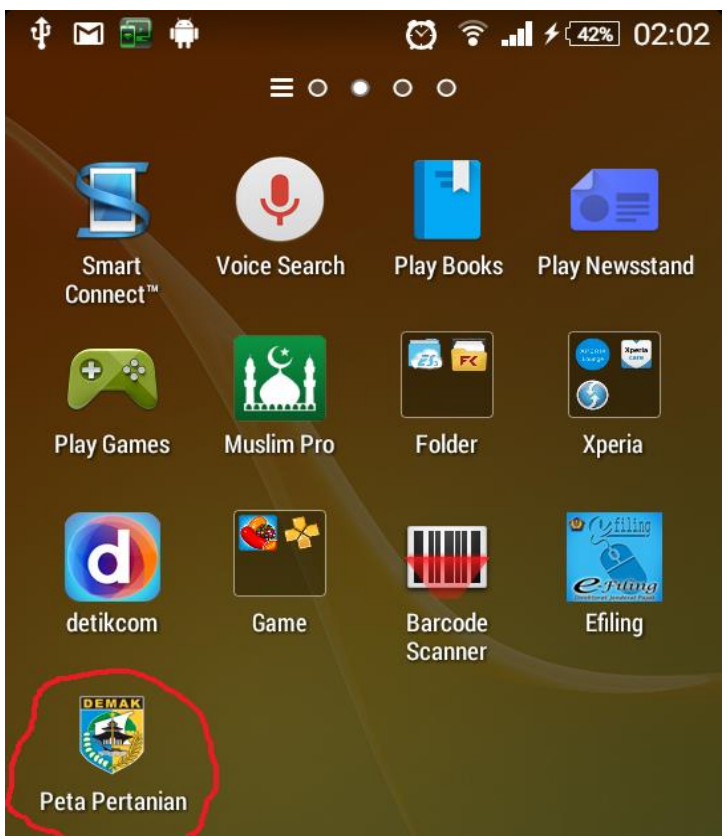

Gambar 2. Halaman Interface

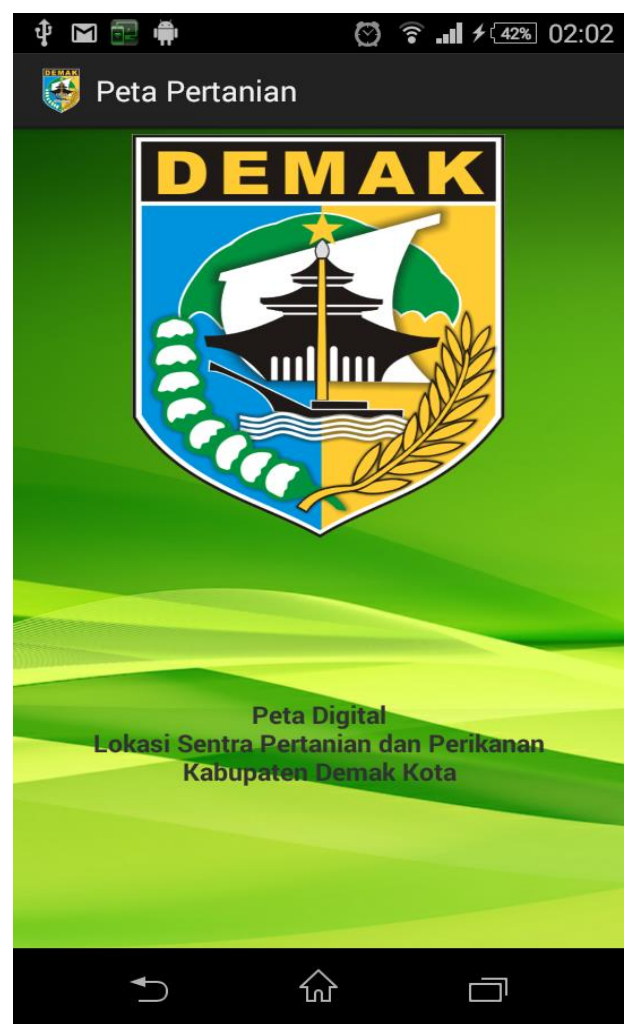

Gambar 3. Halaman utama Aplikasi 


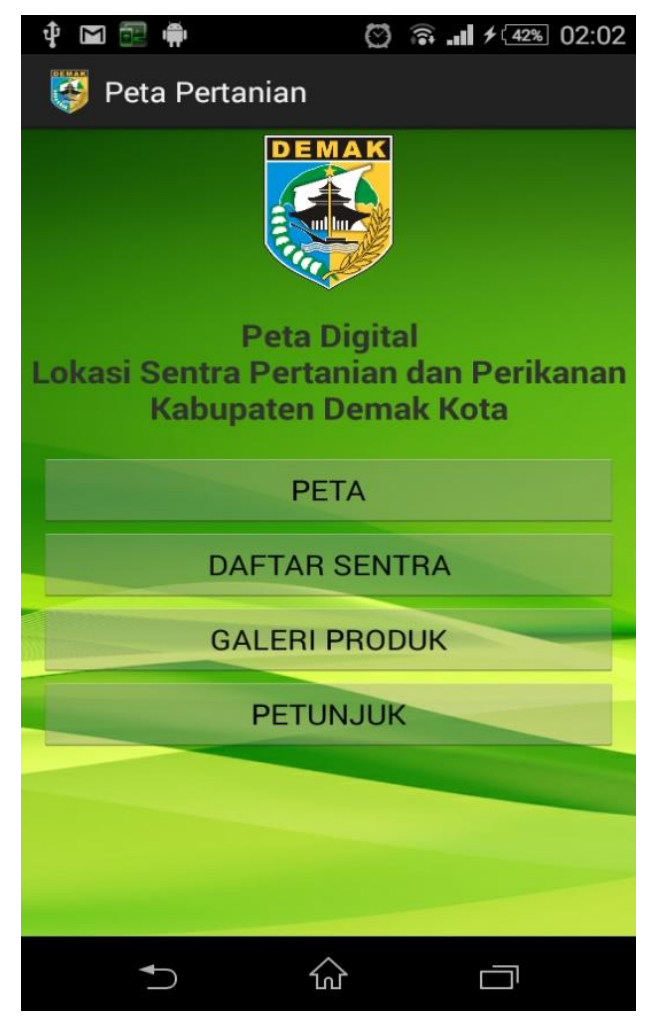

Gambar 4 Menu Utama

Gambar di atas adalah tampilan halaman menu utama aplikasi sentra pertanian dan perikanan yang memiliki 4 tombol menu, yaitu menu Peta (Map) menampilkan Map seluruh Kabupaten Demak beserta Lokasi User berada, menu Daftar Sentra yang merupakn lokasi daerah penyebaran sentra, menu Galeri yang merupakan tampilan hasil dari pusat sentra pertanian dan perikanan,dan Menu Petunjuk digunakan untuk petunjuk penggunaan pada apliksi ini.

2. Tampilan Halaman Map

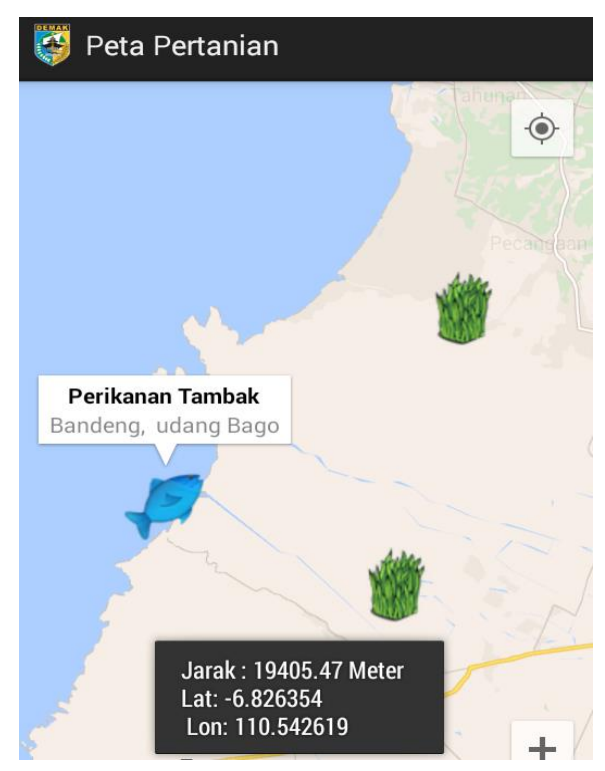

Gambar 5 Peta Perikanan

Halaman menu Map menampilkan peta lokasi yang ada pada aplikasi beserta markernya. Apabila User memilih salah satu marker pada Map maka akan mucul sebagai berikut : 


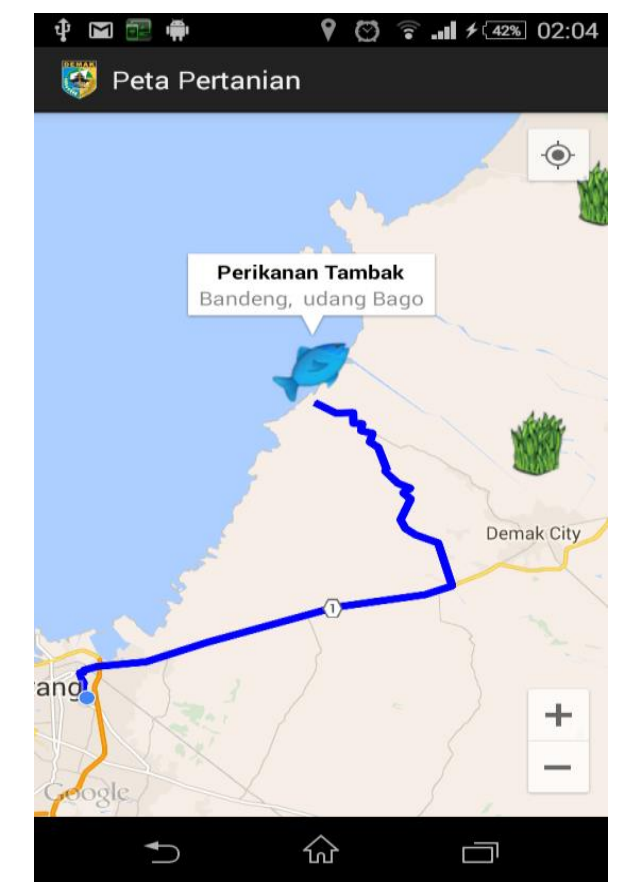

Gambar 6 Tampilan User ke Lokasi Sentra

Gambar diatas menampilkan Lokasi User yang berada di kota Semarang, dan akan langsung menuju jalur ke Lokasi sentra yang dipilih pada salah satu pusat sentra perikanan yang ada di Map Kabupaten Demak.

3. Tampilan Data List Lokasi Sentra

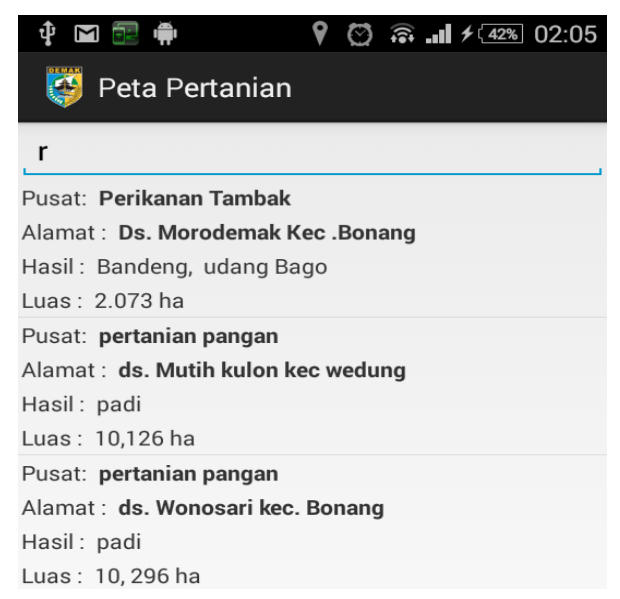

Gambar 7 Tampilan list daftar sentra lokasi.

Gambar di atas menunjukkan menu list daftar sentra yang ada pada Aplikasi Map sentra Pertanian dan Perikanan Kabupaten Demak, dan terdapat kotak dialog yang mana di gunakan untuk pencarian daftar dentra yang ada pada aplikasi ini. 


\section{JURNAL NUSAMBA VOL.3 NO.1 APRIL 2018}

4. Tampilan Menu Galeri Produk

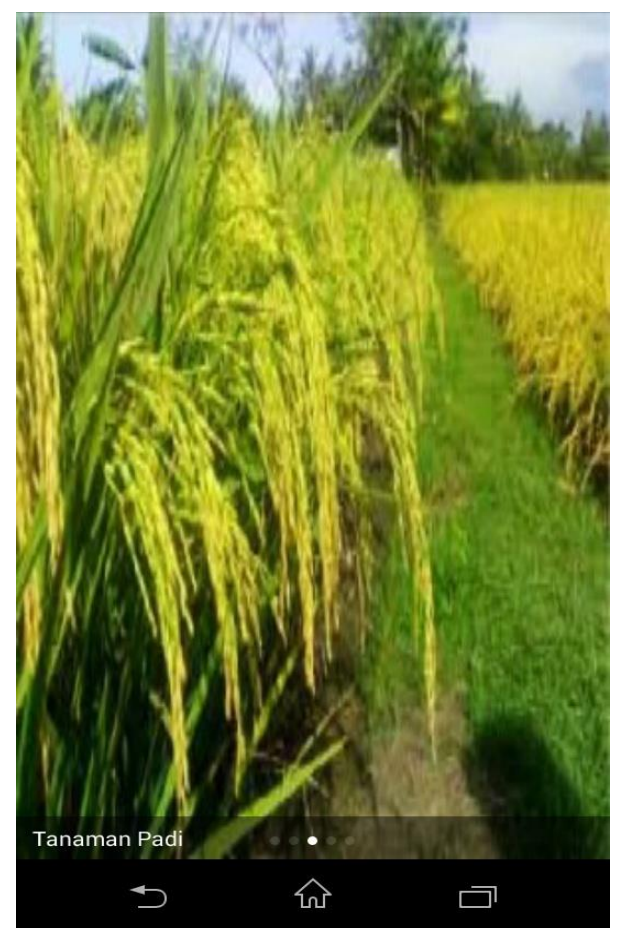

Gambar 8 Halaman Galeri Produk

Halaman galeri produk ini menampilkan gambar-gambar hasil sentra pertanian dan perikanan yang berada pada aplikasi ini.

5. Tampilan Menu Petunjuk

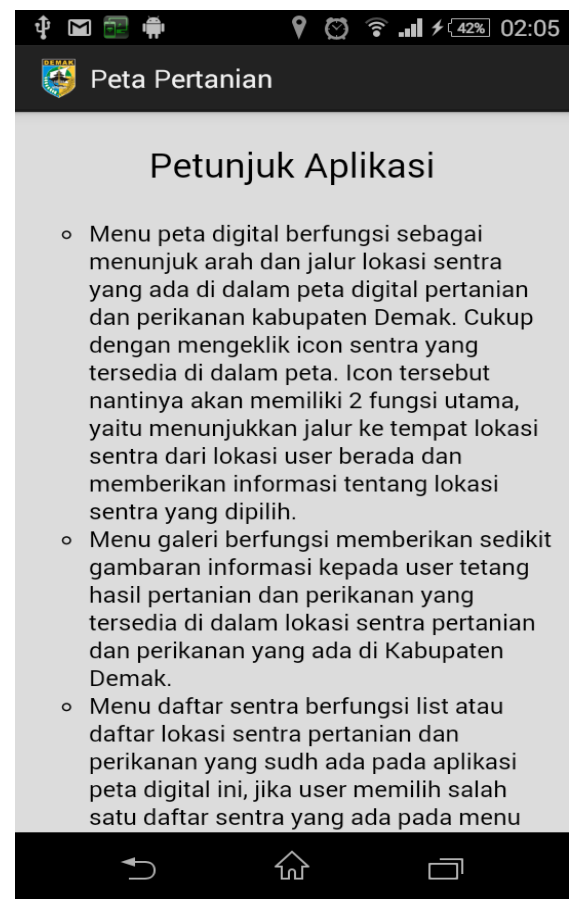

Gambar 9 Petunjuk Penggunaan

Halaman petunjuk ini digunakan untuk memandu user agar dapat memahami cara penggunan pada aplikasi sentra lokasi pertanian dan perikanan ini. 
6. Tampilan Login pada Server Data

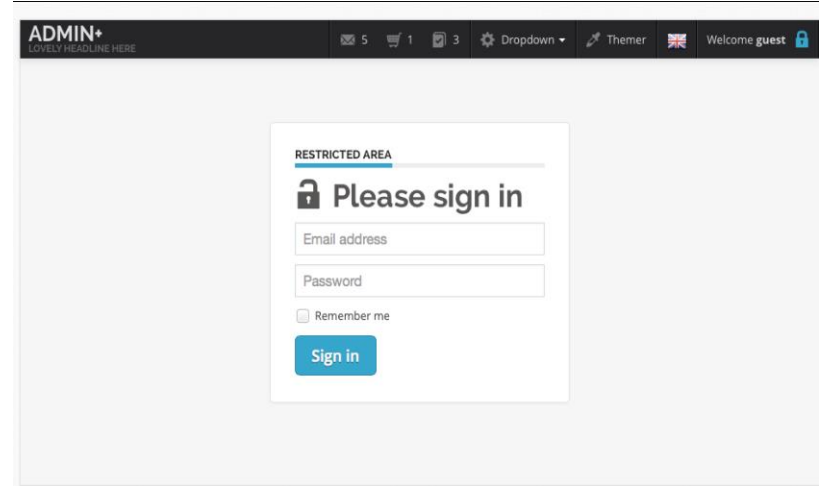

Gambar 10 Tampilan Login Pada Server

Halaman ini digunakan untu proses login pada server agar bisa mengakses data.

7. Tampilan Server Untuk Input Data Sentra

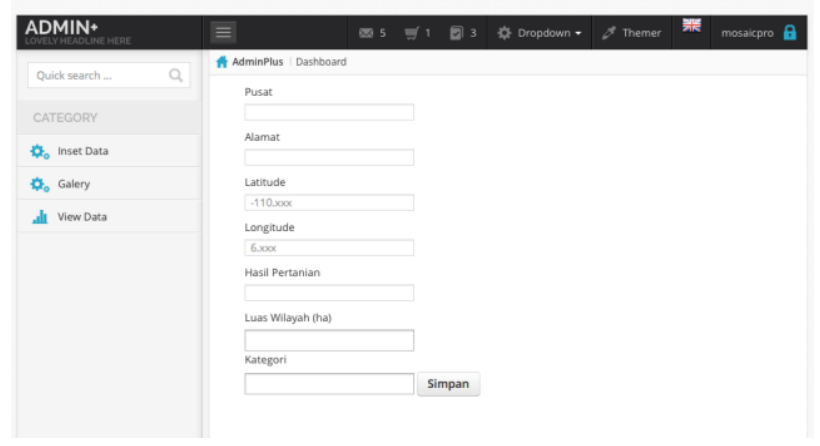

Gambar 11 Form Input Data

Halaman nilai siswa digunakan untuk menambahkan List data pada server, dengan cara menginput data pada kotak diolog yang sudah tersedia, apabila sudah cukup kemudian klik simpan agar data yang dimasukkan dapat tersimpan pada server.

8. Tampilan View Data

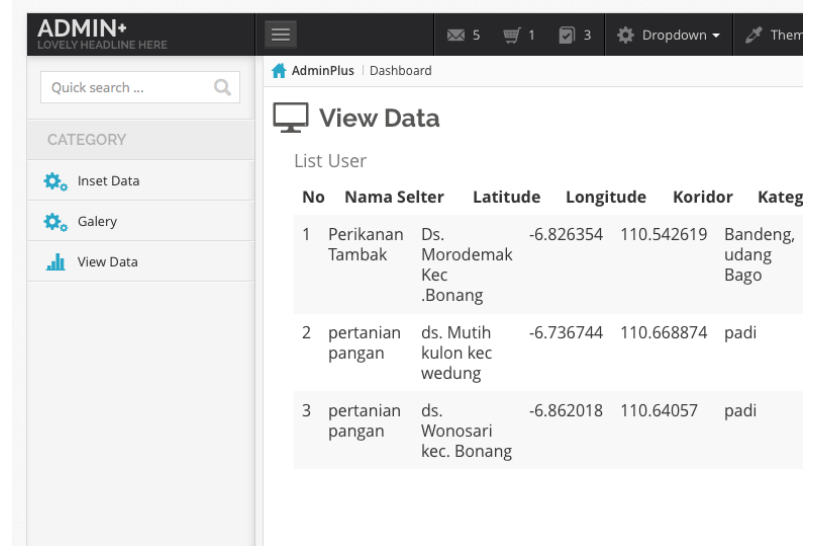

Gambar 12 View Data

Halaman View Data sebagai bukti data yang sudah di input dan hasilnya dapat dilihat dari tampilan ini, apabila data ada kesalahan dapat juga di ubah (edit), bahkan juga dapat di hapus secara langs 


\section{JURNAL NUSAMBA VOL.3 NO.1 APRIL 2018}

9. Tampilan Input Galeri

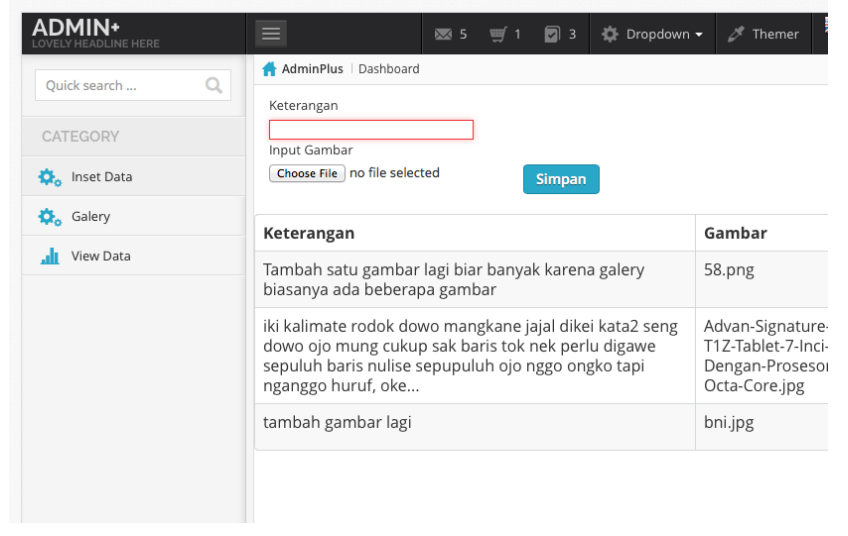

Gambar 13 Tampilan Input Galeri.

Produk Akhir yang dihasilkan dari pengembangan penelitian oleh penulis menggunakan Research and Development (R\&D) telah terbangun suatu prototype berupa Aplikasi pemetaan Digital Sentra Pertanian dan Perikanan di Kabupaten Demak Kota.

Berikut adalah perbandingan antara sistem lama dan sistem baru Aplikasi pemetaan Digital Sentra Pertanian dan Perikanan di Kabupaten Demak Kota :

Gambar 14 Tabel Perbandingan Sistem Lama dengan Sistem Baru

\begin{tabular}{|l|l|l|}
\hline & \multicolumn{1}{|c|}{ Sistem Lama } & \multicolumn{1}{|c|}{ SistemBaru } \\
\hline 1. Jaringan Internet & Tidak ada & $\begin{array}{l}\text { Ada (User menggunakan } \\
\text { jaringan internet untuk } \\
\text { mengakses informasi) }\end{array}$ \\
\hline $\begin{array}{l}\text { 2. Penyampaian } \\
\text { informasi }\end{array}$ & $\begin{array}{l}\text { Melalui pamflet dan papan } \\
\text { nama }\end{array}$ & $\begin{array}{l}\text { Sudah menggunakan } \\
\text { smartphone android } \\
\text { sebagai media informasi }\end{array}$ \\
\hline 3. Sistem Android & Tidak ada & $\begin{array}{l}\text { Ada (Sudah menggunakan } \\
\text { android sebagai sistem) }\end{array}$ \\
\hline 4. Database & Tidak ada & $\begin{array}{l}\text { Ada (Database } \\
\text { menggunakandatabase } \\
\text { SQLite) }\end{array}$ \\
\hline 5. Berbasis Mobile & Tidak ada & $\begin{array}{l}\text { Ada (Penggunabisaakses } \\
\text { informasi dari smartphone } \\
\text { berbasis android dan dapat } \\
\text { di akses tidak terbatas } \\
\text { waktu dan jarak) }\end{array}$ \\
\hline
\end{tabular}

\section{Keterangan :}

Dari isi tabel di atas dapat dijelaskan sistem lama belum menggunakan jaringan internet, penyampaian informasi, sistem Android, database, dan belum menggunakan mobileandroid sedangkan sistem baru lebih dikembangkan lagi sehingga ada jaringan internet untuk akses informasi akademik, keamanan pengguna, menggunakan sistem android, database, dan sudah memakai mobile berbasis android. Produk akhir berupa prototype produk aplikasi sistem informasi akademik berbasis android, sudah melalui pengujian lapangan yang melibatkan user telah dinyatakan bekerja dengan baik sehingga tujuan yang diharapkan yaitu akses informasi hasil pertanian, pencarian lokasi pertanian dan perikanan bisa lebih cepat dan akurat sehingga informasi yang dihasilkan bisa digunakan. 


\section{KESIMPULAN}

Berdasarkan penelitian dengan judul Pemetaan Digital Sentra Pertanian dan Perikanan Untuk Menarik Minat Investor Pada Kabupaten Demak Berbasis Android. Penulis menarik kesimpulan dengan Adanya Pemetaan Digital Sentra Pertanian dan Perikanan ini dapat membantu proses penyampaian informasi hasil dan tempat sentra pertanian dan perikanan menjadi lebih cepat, mudah dan gampang sehingga dapat membantu petani dalam pemasaran hasil pertanian dan membantu investor dalam pencarian lokasi.

\section{DAFTAR PUSTAKA}

Borg, Walter R., \& Gall, M.D. (1983). Educational research: An introduction (4ed). New York \& London: Longman.

Febryantahanuji. (2017). Pemanfaatan Website Sebagai Media Promosi Dan Meningkatkan Peserta Didik Pada (Ma) Madrasah Aliyah Ibrohimiyyah Demak. Jurnal Nusantara Aplikasi Manajemen Bisnis, 2(2), 142-148. doi:10.29407/nusamba.v2i2.842

Febryantahanuji. (2017). "Kesesuaian Jenis Tanah Terhadap Tanaman Untuk Meningkatkan Produktivitas Bisnis Hasil Perkebunan Dengan Geoprocessing”. Jurnal Teknologi Informasi dan Komunikasi. ISSN: 2598-9707.STMIK PROVISI: Semarang.

Randy Dimas. (2013). Jurnal Skripsi "Pemetaan Digital Lokasi Sentra Industri di Kabupaten Jepara pada Platform Android". Ejurnal Universitas Dian Nuswantoro : Semarang.

Rindengan Yaulie. (2013). Jurnal Skripsi “Aplikasi Mobile Rawan Bencana Kota ManadoBerbasis Android”. Universitas Sam Ratulngi : Manado

Riyanto. (2010). “Sistem Informasi Geografis Berbasis Mobile”. Gava Media: Yogyakarta.

Stollberg, Beate. Alexander Zipf. (2008). “Geoprocessing Services for Spatial Decision Support in the Domain of Housing Market Analyses”. AGILE International Conference on Geographic Information Science. University of Bonn: Germany. 